\title{
Editorial
}

\section{0 anos de Arqueologia do Saber: as contribuições aos estudos da linguagem no Brasil}

\author{
Ivânia dos Santos Neves \\ Universidade Federal do Pará \\ http://orcid.org/0000-0002-6738-5254 \\ Pedro NAVARRO \\ Universidade Estadual de Maringá (UEM/CNPq) \\ https://orcid.org/0000-0003-3267-4985
}

Michel Foucault, sem dúvida, representa um dos mais influentes intelectuais do século XXI. Embora tenha falecido em 1984, sua obra, como assinala Deleuze, nos deixou uma significativa caixa de ferramentas teórica, que ajuda a problematizar a verdade e a verticalizar a história do presente. Lido pelas mais diferentes áreas do conhecimento, seus livros, seus ditos e escritos extrapolaram as fronteiras disciplinares.

Um dos aspectos importantes das análises de Michel Foucault sobre as condições de possibilidade do discurso é o modo como ele traz para suas análises a ideia de que o discurso é acontecimento, o que impõe que se recusem temas como origem, causalidade, espírito de época, por exemplo. A noção de acontecimento devolve aos discursos o seu caráter de irrupção, ao mesmo tempo em que sinaliza para uma fratura no arquivo.

Foucault propôs um tipo de história diferente daquela que privilegiava os grandes sujeitos, a chamada macro-história. Deixou de olhar para as grandes batalhas, as importantes lutas de monarcas, para se voltar para os pequenos acontecimentos (a micro-história), que fazem a história mudar seu curso. História não mais reduzida ou referida a um desejo totalizante de um sujeito originário, mas história que se faz entre as relações discursivas, que coloca o sujeito não como centro, mas como disperso nas posições discursivas que assume no discurso.

No ano de 2019, comemoramos os 50 anos da publicação de "A Arqueologia do Saber", leitura fundamental para pesquisadores, professores e estudantes interessados nos estudos do discurso com Michel Foucault no Brasil. Neste livro, o autor se posiciona criticamente diante de um projeto positivista de história tradicional por meio de uma série de oposições. Assim, contrapondo-se a uma história que se desenvolve em 
uma continuidade linear e simples, o autor, fundamentado em Nietzsche, Bachelard e Canguilhem, propõe uma genealogia cujo motor é a descontinuidade.

Lançada em língua portuguesa em 1972, pela Editora Vozes, simultaneamente, no Brasil e em Portugal, atualmente, “A Arqueologia do Saber”, como indicam as bases de dados de Teses e Dissertações da Capes, representa uma das principais referências nas pesquisas dedicadas aos estudos do discurso, na área de Letras, no Brasil.

Desde 1999, um grupo constituído por professores de diferentes universidades do Brasil vem se debruçando sobre os pressupostos teóricos e analíticos presentes nessa obra com o intuito de compreendê-los no interior da chamada Linguística teórica (subárea da Linguística), mais especificamente, nos estudos em Análise do Discurso. Nesses 20 anos, esse grupo se fortaleceu e criou um Grupo de Trabalho na ANPOLL, intitulado Estudos Discursivos Foucaultianos, iniciado em 2018.

Organizado por este GT, em outubro de 2019, aconteceu na Universidade Estadual de Maringá o evento “(Re)Ler A Arqueologia do Saber Hoje nos Estudos Discursivos da Linguagem: 50 Anos", cuja finalidade maior foi oportunizar a troca de experiências acadêmicas entre pesquisadores, professores e alunos do país que se dedicam ao estudo da constituição, formulação e circulação dos discursos na sociedade contemporânea.

Como mais uma ação do GT Estudos Discursivos Foucaultianos, em comemoração aos 50 anos de "A Arqueologia do Saber", agora apresentamos este dossiê da Revista Moara, que recebeu quase quarenta artigos para serem avaliados. Para nossa felicidade, recebemos artigos de todas as regiões do Brasil e podemos observar uma promissora geração de jovens pesquisadores que com bastante competência amplia nossas discussões e objetos.

Ao final do processo de avaliação, decidimos por dividir o dossiê em Volume I, que agora entregamos ao público e Volume II, que será publicado no primeiro semestre de 2021. Neste primeiro volume, selecionamos onze artigos e uma resenha sobre "Arqueologia do Saber".

No artigo de abertura, "Estudos discursivos foucaultianos: questões de método para análise de discursos", Pedro Navarro, a partir de uma perspectiva mais teórica que analítica, problematiza o chamado método arqueogenealógico e traça um fio condutor em torno de três interrogações: precisamos ainda nos filiar à chamada Análise de Discurso francesa? Michel Foucault propôs ou não um método de análise das formações 
discursivas sobre as quais se debruçou para descrever suas regras de formação? $\mathrm{O}$ último Foucault ainda é um arqueologista?

Diante da proliferação de discursos de intolerância e ódio dirigidos contra a população pobre nos últimos anos, responsabilizando-a pela crise econômica e desordem do país, o segundo artigo, "Biopolítica, discurso e controle da população pobre", de Kátia Meneses de Sousa, problematiza os enunciados e as condutas que envolvem o corpo pobre, atendendo ao objetivo mais amplo que é o de conhecer alguns traços do que somos hoje, do que é nossa sociedade.

Maurício Neves Correa, no terceiro artigo "Entre as almas e as câmeras: Arqueogenealogias do corpo indígena" analisa os limites éticos e estéticos das histórias filmadas sobre corpos indígenas em produções de temporalidades diferentes, postadas na WEB, que se ligam e se desligam ao passado e ao presente a partir das teias do discurso, com o objetivo de reativar fragmentos de lutas dos povos indígenas e empreender uma crítica do presente.

No quarto artigo, "Infames e penetras no universo da leitura: princípios da arqueologia foucaultiana em uma análise de discursos sobre essa prática", de Luzmara Curcino, empreende uma análise de discursos sobre a leitura a partir de notícias que emergem com relativa frequência, com histórias de pessoas que viviam na miséria e graças à leitura melhoraram de vida. A autora mostrou como a leitura, nestes casos, é evocada como álibi para justificar vergonhosas desigualdades socioculturais e para naturalizar certas formas de exercício do poder, e não como uma prática em seu potencial efetivamente emancipatório.

Em "Cortem-lhe a cabeça: a atualidade desse enunciado mutilando corpos de mulheres e subjetividades", o quinto artigo, Denise Gabriel Witzel partiu do enunciado Cortem-lhe a cabeça, da Rainha de Copas, em "Alice no País das Maravilhas", para analisar a rede de sentidos tramada em torno do significante "cabeça" transformado, historicamente, em símbolo de poder e justiça. Ela identificou articulações que esse enunciado estabeleceu com a história das mulheres e como sua memória, hoje presente também em postagens de Facebook sobre um caso de feminicídio/decapitação, continua (re)produzindo antigas práticas de mutilação de corpos e de subjetividades.

No sexto artigo, "Uma leitura arqueogenealógica do racismo estrutural em instituições do sistema de justiça do Maranhão", Mônica da Silva Cruz analisa um processo coletado no Sistema de Justiça do Maranhão, para demonstrar como a negação 
do racismo pavimenta práticas de impunidade em instituições do sistema de justiça maranhense, estado onde existe uma das maiores populações negras do país.

Em "Cartografias da Resistência: as vozes das manifestações de rua", o sétimo artigo, Regina Baracuhy propõe uma cartografia das práticas discursivas, materializadas nos cartazes e faixas das manifestações de rua ocorridas no Brasil, em João Pessoa e em São Paulo (2019-2020). Ela analisa o corpo investido de poder e com a rua é tomada como palco de produção de subjetividades.

Em "Corpo-espaço organização e funcionamento de uma noção discursiva", o oitavo artigo, Marisa Martins Gama-Khalil e Nilton Milanez apresentam o delineamento da noção corpo-espaço, ancorada nos estudos discursivos de Michel. Para a realização do batimento entre a noção teórica de corpo-espaço e o movimento de análise, eles elegeram para a análise duas narrativas, uma literária e outra audiovisual: o conto " $\mathrm{O}$ gato preto", de Edgar Allan Poe (1843) e o filme dele decorrente, "The Black Cat" (1934), dirigido por Edgar G. Ulmer.

No nono artigo, "Foucault escritor: o arquivista e o eu-enunciado na arqueologia", Carla Luzia Carneiro Borges e Renailda Ferreira Cazubá apresentaram um Michel Foucault que se define como escritor e arquivista, o sujeito como um ser das dispersões e contradições no livro "A Arqueologia do Saber”. As autoras analisaram o processo de subjetivação de Foucault, seu movimento em espiral, no interior de sua obra e destacaram os enunciados que acusam o acontecimento da escritura foucaultiana.

O décimo artigo, "Do enunciável ao visível: as condições de possibilidade do videopoema "Vida em Branco"”, de Antônio Fernandes Júnior e Amanda Soares Mantovani, discorreu sobre as imbricações discursivas e não discursivas (enunciável e visível) que objetivaram a noção de arte entre o final de 2019 e o início de 2020, no Brasil. Os autores tomaram o videopoema "Vida em branco" (2020), de Zélia Duncan com sua estética de resistência e sua viralização nas redes sociais como um acontecimento discursivo.

No último artigo, “A Batalha do Livramento: exposição e silenciamento entre os Tembé-Tenethara", Nassif Ricci Jordy Filho e Ivânia dos Santos Neves analisam um acontecimento discursivo que envolveu a prisão ilegal de 77 indígenas TembéTenetehara em 1996. Os autores tomaram como corpus de análise as narrativas orais dos Tembé e as fotografias dos dois principais jornais impressos do estado do Pará para mostrar as condições de possibilidades históricas dos processos de silenciamento e visibilidade da luta dos Tembé pela efetiva posse de suas terras. 
Gabriel Pereira Castro e Heloísa Reis Curvelo-Matos investigam os nomes de três bairros na cidade de São Luís, no estado do Maranhão, a partir de siglas institucionais, com o objetivo de descrever o léxico toponímico e a documentação do processo habitacional da cidade em seus aspectos antropoculturais e físicos.

No âmbito dos estudos de tradução intralingual, Silvia Helena Benchimol Barros, Paulo Santiago de Sousa, Marciano Cabral dos Santos e Valéria Jane dos Reis

Borges do Carmo encerram essa seção estudando a terminologia usada no Garimpo do Macaco em Cachoeira do Piriá - PA, a partir de glossário elaborado durante a pesquisa, e analisam o uso e o registro dos significados específicos atribuídos a 58 termos selecionados. Finalizando este primeiro volume do dossiê, a resenha do livro "A Arqueologia do Saber", um roteiro de leitura da obra, feita por Daniel Loureiro Gomes, Marília Leite e Ivânia dos Santos Neves.

Desejamos que as análises e as discussões deste dossiê possam contribuir para os estudos da linguagem no Brasil

Boa leitura a todas e todos! 